\title{
RECARGA E CONEXÃO HIDRÁULICA NO SISTEMA AQUÍFERO GRANULAR-FISSURAL NO CAMPUS PAMPULHA DA UFMG, BELO HORIZONTE, MG
}

João Pedro MARQUES RIBEIRO

Leila Nunes Menegasse VELÁSQUES

Carlos Alberto de CARVALHO FILHO

\begin{abstract}
RESUMO
Nesse estudo foram analisadas a recarga e a conexão hidráulica entre os aquíferos granular e fissural do sistema aquífero granular-fissural no campus Pampulha da UFMG, em Belo Horizonte, Minas Gerais. Na área, o aquífero granular é livre, se sobrepõe ao fissural, e é constituído por aluviões, colúvios e solo residual, enquanto o aquífero fissural é livre a semi-confinado, representado por gnaisses, granitos e diques de diabásio do Complexo Belo Horizonte. A precipitação média anual é de 1.404,8 mm com maior incidência entre outubro e março. Foi realizado um monitoramento automatizado e manual do nível d'água por 8,5 meses que envolveu completamente a estação chuvosa, de agosto/2012 a abril/2013. As medidas automatizadas foram executadas mediante a instalação de transdutores de pressão em 3 piezômetros e 3 poços profundos inativos, com leituras a cada 15 minutos, enquanto o monitoramento manual foi realizado semanalmente em outros 2 poços profundos inativos e piezômetro. A caracterização da conexão hidráulica foi feita estimando-se o tempo de resposta do nível d'água de cada aquífero à precipitação e o tempo decorrido entre a recarga direta do meio granular e a recarga indireta deste para o meio fissural. Para o cálculo da conexão hidráulica foram empregadas técnicas de análise de funções de correlação cruzada. Os resultados indicaram que o tempo de resposta à recarga do aquífero fissural a partir do granular foi de menos de $24 \mathrm{~h}$. A recarga para o aquífero granular, calculada pela variação do nível d'agua, foi de 264 a $390 \mathrm{~mm}$ (média de $775.000 \mathrm{~m}^{3}$ ), $28 \%$ a $41 \%$ da precipitação, respectivamente. Desse total, avaliou-se, preliminarmente, que cerca de $14 \%\left(109.200 \mathrm{~m}^{3}\right)$ recarregam o aquífero fissural.
\end{abstract}

Palavras-chave: Monitoramento de nível d'água; Recarga; Conexão hidráulica; Análise de correlação cruzada.

\footnotetext{
ABSTRACT

RECHARGE AND HYDRAULIC CONNECTION BETWEEN POROUS AND FISSURAL AQUIFER UNITS OF THE CAMPUS PAMPULHA AQUIFER SYSTEM BELO HORIZONTE, MG. The aim of this study was estimate the recharge and hydraulic connection between the granular and fissured aquifers of the aquifer system in the Pampulha campus of the UFMG, in Belo Horizonte, Minas Gerais, was analyzed. In the area, the granular aquifer is unconfined, overlaps the fissural, and consists of alluvium, colluvium and residual soil, while the fissured aquifer is unconfined to semiconfined, represented by gneisses, granites and dikes of the Belo Horizonte Complex. The mean annual rainfall is $1,404.8 \mathrm{~mm}$, with the highest incidence between October and March. An automated and manual monitoring of the water level for 8.5 months was carried out that completely involved the rainy season, from August/2012 to April/2013. The automated measurements were performed by installing pressure transducers in 3 piezometers and 3 inactive deep wells, with readings every 15 minutes, while manual monitoring was performed weekly in other 2 deep inactive wells and a piezometer. The characterization of the hydraulic connection was made by estimating the response time
} 
of the water level of each aquifer to the precipitation and the time elapsed between the direct recharge of the granular medium and the indirect recharge of this to the fissural medium. Cross-correlation function analysis techniques was used to calculate the hydraulic connection. The results indicated that the response time to recharge of the fissural aquifer from the granular was less than $24 \mathrm{~h}$. The recharge for the granular aquifer, calculated by the variation of the water level, was 264 to $390 \mathrm{~mm}$ (average of $\left.775,000 \mathrm{~m}^{3}\right), 28 \%$ to $41 \%$ of the precipitation, respectively. Of this total, it was preliminarily estimated that about $14 \%\left(109,200 \mathrm{~m}^{3}\right)$ recharge the fissural aquifer.

Keywords: Water level monitoring; Recharge; Hydraulic connection; Cross-correlation analysis.

\section{INTRODUÇÃO}

As características climáticas, geológicas e de ocupação do solo controlam a dinâmica e a quantidade de água que recarrega os aquíferos, portanto, seu conhecimento é imprescindível para o gerenciamento dos mananciais subterrâneos. Entende-se como recarga a parte da infiltração de água que percola até o aquífero, enquanto as demais parcelas ficam retidas na zona não saturada e alocam-se nas franjas capilares ou constituem o fluxo subsuperficial (FEITOSA \& MANOEL FILHO 2008).

De acordo com WAHNFRIED \& HIRATA (2005) existem dois tipos de recarga, a direta e a indireta. $\mathrm{O}$ primeiro tipo ocorre quando a precipitação pluvial atinge diretamente o aquífero nas suas áreas aflorantes ou através das rochas ou solos sobrejacentes. A recarga direta é predominante nos aquíferos livres, enquanto nos confinados tem lugar apenas em suas porções não confinadas. A recarga indireta se dá principalmente a partir das drenagens superficiais, tais como rios e lagos que cedem água para o aquífero livre. A ação antrópica, a partir da irrigação e das perdas nas estruturas de adução, também pode contribuir na recarga indireta e artificial dos aquíferos. Da mesma forma, processos de drenança através do aquitardo para o aquífero confinado também constituem um tipo de recarga indireta. As áreas disponíveis para ocorrência da recarga direta e indireta são denominadas zonas de recarga, as quais são providas de características geológicas e pedológicas propícias à infiltração.

Um parâmetro importante no contexto da infiltração é a intensidade das chuvas: quando muito intensas e precipitadas em solos de pouca permeabilidade, as chuvas acarretam um maior escoamento superficial, ao passo que chuvas menos intensas favorecem o processo de infiltração da água no solo, através da pressão gravitacional, aumentando a recarga (REBOUÇAS 2002).

Os aquíferos fraturados estão presentes em todas as regiões do Brasil, principalmente nas regiões Nordeste, Sudeste e Norte, representados por diversos tipos de rochas, entre as quais os gnaisses, xistos, filitos, granitos, metacalcários e quartzitos pré-cambrianos (REBOUÇAS 2002). A água nestes aquíferos encontra-se armazenada nas fraturas, tornando a produtividade dos poços dependente das características do fraturamento, tais como a intensidade, abertura e a conectividade entre as descontinuidades. Em geral, esse tipo de aquífero tem produtividade inferior à média dos aquíferos sedimentares; mesmo assim, por se encontrarem em regiões carentes de recursos hídricos, têm uma função estratégica muito importante para o abastecimento público (ANA 2007).

Em aquíferos fraturados de regiões de clima úmido, uma das principais formas de infiltração e, consequentemente, de recarga, é através do manto de intemperismo sobrejacente, constituído de solo residual ou transportado. Esses depósitos granulares facilitam o armazenamento da água pluvial infiltrada, que é percolada até o aquífero fraturado, configurando, portanto, uma recarga indireta (VASCONCELOS 2005).

A quantificação da recarga indica a quantidade de água que efetivamente atinge o aquífero e o entendimento de seu processo permite identificar os elementos naturais e ou antrópicos atuantes como facilitadores ou como obstáculos à efetivação da infiltração.

O presente trabalho teve por objetivo quantificar a recarga no sistema aquífero granular-fissural, bem como avaliar o grau de conexão hidráulica entre eles, na área do campus da Pam- 
pulha da Universidade Federal de Minas Gerais (UFMG), localizada na cidade de Belo Horizonte, MG. Os resultados aqui apresentados aprofundam o conhecimento adquirido em trabalho anterior (MARQUES RIBEIRO et al. 2014) que teve como objetivo fazer uma análise preliminar sobre a recarga do aquífero. A fim de complementar esta análise preliminar foi feito o monitoramento automatizado (com uso de transdutores de pressão) dos níveis freáticos dos poços. Com isso houve um aumento significativo na quantidade de dados, o que permitiu uma investigação mais robusta, fazendo-se valer de métodos estatísticos como a Função de Correlação Cruzada e a Função de Auto Correlação, assim evidenciando o tempo que leva para que um evento de chuva consiga interferir no nível freático e por quanto tempo este evento ainda estará interferindo no nível freático.

\section{LOCALIZAÇÃO E CARACTERÍSTICAS DA ÁREA DE ESTUDO}

O campus universitário da UFMG está localizado na região da Pampulha, no setor norte da cidade de Belo Horizonte (Figura 1). A área do campus comporta parte das sub-bacias dos córregos Engenho Nogueira e Mergulhão, entretanto, somente a porção média da primeira sub-bacia foi alvo desse estudo.

O campus da UFMG ocupa uma área de $3.340 .000 \mathrm{~m}^{2}$, dos quais $2.500 .000 \mathrm{~m}^{2}$ constituem o objeto do estudo, o qual encontra-se delimitado pelas coordenadas UTM 607.000 e 610.000 Oeste, e 7.803.500 e 7.802.000 Sul, onde estão as edificações da UFMG e do Centro de Desenvolvimento da Tecnologia Nuclear (CDTN) (Figura 1).

De acordo com a reitoria da UFMG, no ano de 2012, o campus Pampulha era frequentado por 36.844 pessoas dentre alunos, professores e funcionários. $\mathrm{O}$ abastecimento hídrico do campus, tanto da UFMG como do CDTN, é feito principalmente pela Companhia de Saneamento de Minas Gerais (COPASA - MG). Dois poços no Campus abastecem a escola de Veterinária da UFMG, e um abastece o CDTN, complementando a distribuição da COPASA.

\section{Contexto geotectônico e geológico local}

O município de Belo Horizonte insere-se na grande unidade geotectônica conhecida como Cráton do São Francisco, extenso núcleo crustal do centro-leste do Brasil. Predominam as rochas arqueanas do Complexo Belo Horizonte e sequên- cias supracrustais paleoproterozóicas (COSTA 2002). O complexo Belo Horizonte é formado por rochas gnáissicas e migmatíticas parcialmente milonitizadas. Estas rochas apresentam a característica de possuir fraturas abertas e penetrativas, mas distantes, em metros, umas das outras, resultando em pouca intercomunicação entre elas, comprometendo o armazenamento (COSTA 2002).

As fraturas do Complexo Belo Horizonte possuem mergulhos verticais a subverticais e paredes lisas. Predominam fraturas na direção NE-SW, abertas, confirmadas pela presença de diques clásticos, e NW-SE, preenchidas por diques máficos de segunda geração (CPRM 2001).

$\mathrm{Na}$ área de estudo as rochas do Complexo Belo Horizonte, encontram-se representadas por seus produtos de alteração intempérica (CARVALHO FILHO 1997): solos residuais, depósitos cenozóicos aluviais (cascalhos, areias e argilas) e coluviais argilo-arenosos. O autor distinguiu no Complexo Belo Horizonte na área de estudo duas unidades: (i) substrato cristalino são e (ii) manto de intemperismo, conforme figura 2. Na porção NE da área de estudo ocorre uma possante lente de argila que, de acordo com a seção geológica, atravessa os poços P10 e P9 (Figura 2). Esta lente de argila deve atuar como uma barreira hidráulica, configurando aquíferos suspensos no local.

\section{Hidrologia e clima}

O Córrego Engenho Nogueira, pertencente à bacia hidrográfica do ribeirão do Onça, percorre $1,5 \mathrm{~km}$ ao longo da área de estudo e se encontra canalizado na maior parte do campus, por 1,25 $\mathrm{km}$. O clima da região, segundo a classificação de Köppen, é tropical de altitude com inverno seco e verão chuvoso ( $\mathrm{Cwa}$ ). A temperatura média anual é de $21,5^{\circ} \mathrm{C}$, a precipitação média anual de $1.479,5$ $\mathrm{mm}$ e a evapotranspiração potencial, calculada pelo método de Penman, é de $1.404,8 \mathrm{~mm}$, e se referem ao período de monitoramento de 1997 a 2000 (BEATO et al. 2003).

CARVALHO FILHO (1997) calculou a evapotranspiração real (ETR) para a região do campus da UFMG, pelo método de Thornthwaite, obtendo 1083,3 $\mathrm{mm}$ no ano de 1996.

O período de deficiência hídrica estende-se de maio a outubro, com maior déficit em agosto. A partir de novembro se inicia o período chuvoso, com excedente hídrico de dezembro a março, variando de $234 \mathrm{~mm}$ a $477 \mathrm{~mm}$, calculado por BEATO et al. (2003) para os anos de 1997 a 2000. 


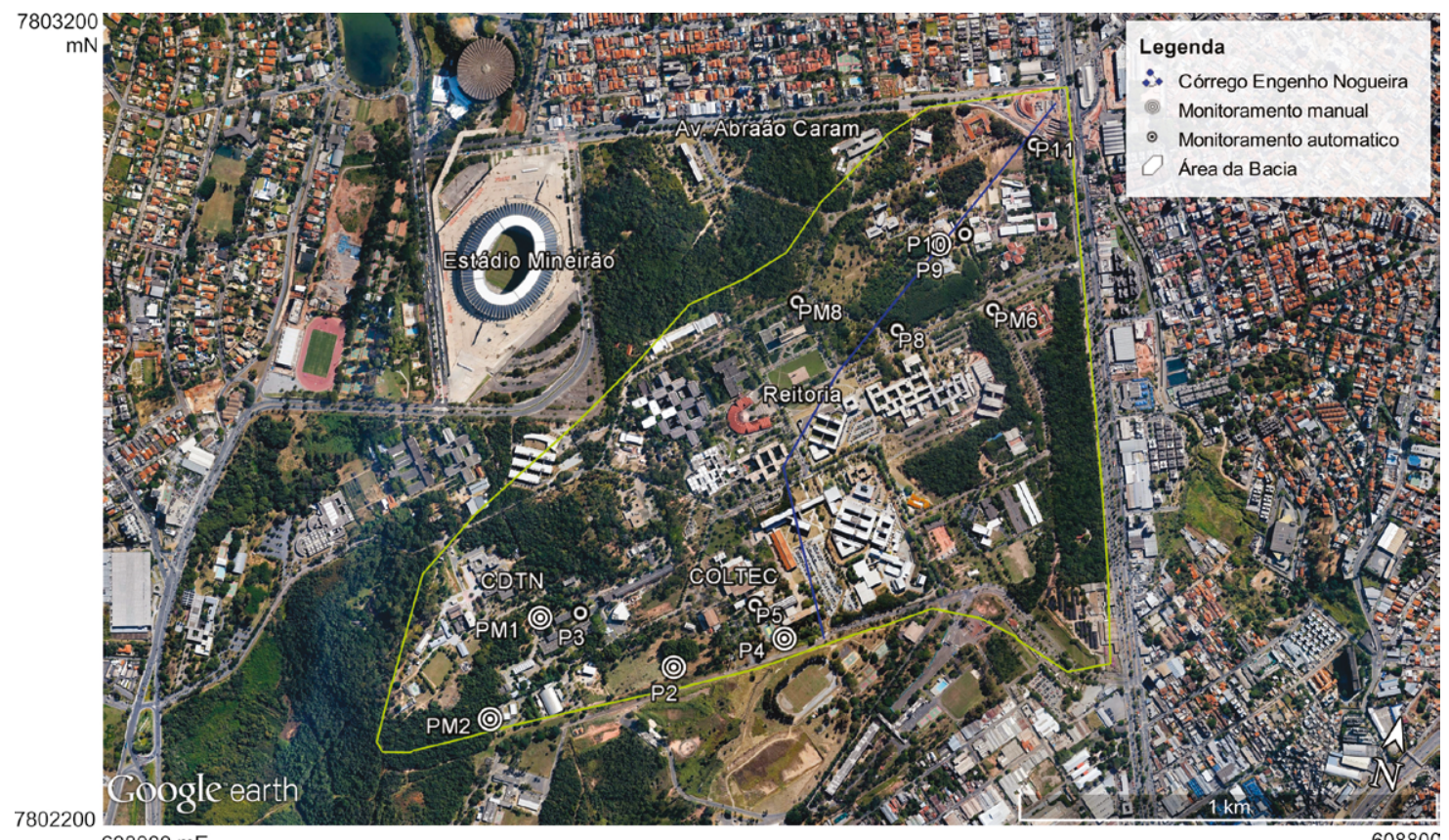

$608000 \mathrm{mE}$

$60880 \mathrm{C}$
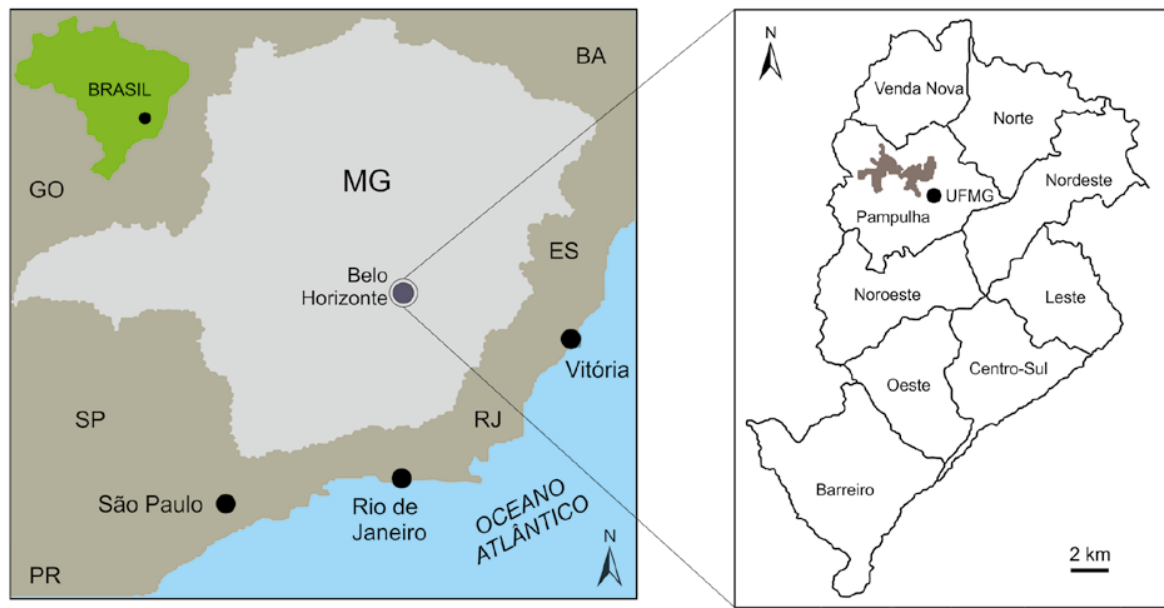

FIGURA 1 - Área de estudo com a localização dos poços e piezômetros monitorados (PM = poço de monitoramento/piezômetro, $\mathrm{P}=$ poço tubular). P5, P9 e P11 correspondem a poços tubulares utilizados em estudo anterior (MARQUES RIBEIRO et al. 2014).

\section{Hidrogeologia}

A área de estudo assenta-se sobre o aquífero fraturado, constituído de rocha sã (granitos, gnaisses, migmatitos e milonitos), sotoposta ao manto de intemperismo e aos depósitos colúvio-aluvionares.

O manto intempérico e sua cobertura constituem um aquífero poroso granular, sob condição livre, com espessura média de $44 \mathrm{~m}$. Já o aquífero fraturado, de natureza heterogênea e anisotrópica, pode se apresentar livre a semiconfinado.

Independentemente da rocha formadora e da natureza do solo que o recobre, o aquífero fraturado está intercomunicado com o aquífero granular que o sobrepõe (COSTA 2002). Assim, a recarga do aquífero fraturado ocorre, majoritariamente, pela infiltração de águas pluviais através das coberturas detríticas, isto é, através dos aquíferos granulares e respectivo manto de alteração. 

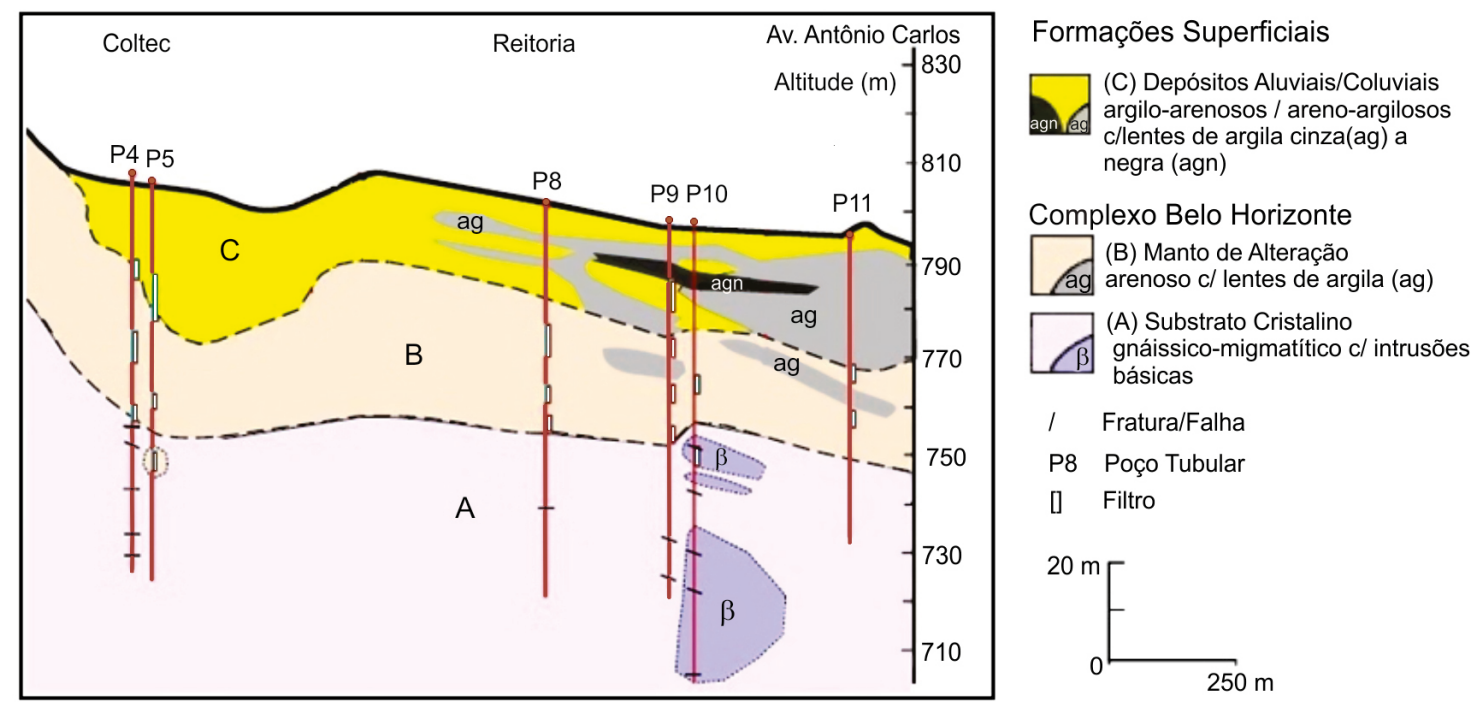

FIGURA 2 - Seção geológica da área de estudo. Adaptado de CARVALHO FILHO (1997).

\section{MATERIAIS E MÉTODOS}

3.1 Inventário, seleção e monitoramento do nível estático dos poços

Foram inventariados 13 poços profundos e 9 piezômetros (poços de monitoramento no aquífero poroso), dos quais foram selecionados apenas os que estavam em condições físicas e hidráulicas de serem utilizados (Tabela 1).

Conforme a tabela 1 os poços profundos foram classificados de acordo com a origem da entrada de água em: "fraturado" (entrada exclusiva da rocha fraturada) e "misto" (entradas no meio granular e na rocha fraturada). No caso de poço com entradas de água nos meios granular e rochoso fraturado, cujo nível de água dinâmico se posicionas- se abaixo do filtro da porção granular, foi também classificado como "fraturado". Os poços profundos fraturados foram ainda classificados de acordo com a pressão da água em: "livre" e "semiconfinado". Foi considerado poço semiconfinado aquele cujo nível estático se encontrava acima da base do aquífero granular. Todos os poços mistos foram admitidos como sendo do tipo livre, indicando existência de conexão hidráulica entre ambos os aquíferos.

As informações sobre os piezômetros, obtidas junto ao Departamento de Obras do campus universitário (DPFO), encontram-se na tabela 2. A caracterização textural do manto de intemperismo foi obtida pelo percentual de cada textura (areia, silte, argila) em relação à profundidade do piezômetro.

TABELA 1 - Características dos poços profundos quanto à pressão da água.

\begin{tabular}{ccccc}
\hline \multirow{2}{*}{ Poço } & $\begin{array}{c}\text { Tipo de } \\
\text { aquifero }\end{array}$ & Pressão & \multicolumn{2}{c}{$\begin{array}{c}\text { Coordenadas UTM } \\
\text { (Datum WGS84) }\end{array}$} \\
\cline { 3 - 5 } & \multicolumn{2}{c}{ Sem dados } & Norte (m) & Leste (m) \\
\hline P2 & Fraturado & Semiconfinado & 7802250,00 & 608079,00 \\
\hline P3 & Misto & Livre & 7802294,95 & 608579,71 \\
\hline P4 & Fraturado & Livre & 7803130,21 & 608710,02 \\
\hline P8 & Fraturado & Semiconfinado & 7803394,26 & 608828,76 \\
\hline P10 & & & & \\
\hline
\end{tabular}


TABELA 2 - Profundidade dos piezômetros e textura do manto de intemperismo.

\begin{tabular}{cclcc}
\hline Piezômetro & $\begin{array}{c}\text { Profundidade } \\
(\mathrm{m})\end{array}$ & \multicolumn{1}{c}{ Termos texturais } & \multicolumn{2}{c}{$\begin{array}{c}\text { Coordenadas UTM } \\
\text { (Datum WGS84) }\end{array}$} \\
\cline { 3 - 4 } PM1 & 12,0 & $\begin{array}{l}50 \% \text { de silte arenoso a areia; } 50 \% \text { de solo } \\
\text { residual com estruturas da rocha }\end{array}$ & Norte $(\mathrm{m})$ & Leste $(\mathrm{m})$ \\
\hline PM2 & 10,5 & $\begin{array}{l}32 \% \text { de argila siltosa; 37\% de silte arenoso a } \\
\text { areia; 31\% de solo residual com estruturas da } \\
\text { rocha }\end{array}$ & 7802271,79 & 608085,58 \\
\hline PM6 & 14,8 & $50 \%$ de silte arenoso; $50 \%$ de silte & 7801967,96 & 607991,36 \\
\hline PM8 & 8,0 & $\begin{array}{l}39 \% \text { de silte argiloso; } 11 \% \text { de argila orgânica; } \\
16 \% \text { de argila preta; 34\% de silte arenoso }\end{array}$ & 7803129,77 & 608474,15 \\
\hline
\end{tabular}

Visando identificar a conexão hidráulica entre os aquíferos poroso e fraturado, os critérios considerados para a escolha dos pontos para o monitoramento automatizado foram: a) a máxima proximidade entre um piezômetro e um poço profundo, de modo que o piezômetro pudesse descrever a sazonalidade do nível de água do aquífero granular sobreposto ao aquífero fissural representado pelo poço profundo; b) poços profundos com entradas de água exclusivamente pelas fraturas; c) piezômetro e poço profundo distantes de poços em operação para evitar interferência do bombeamento no nível d'água.

Desse modo, foram selecionados dois pares de poços profundos e piezômetros próximos entre si e que atendiam a todas essas condições: P8/PM8 e P10/PM6 (Figura 1). Um terceiro par de poços do CDTN (P3/PM1) foi selecionado, ainda que P3 estivesse em funcionamento, visando apenas a determinação de parâmetros hidráulicos do aquífero.

O monitoramento automatizado foi realizado com transdutores de pressão, com frequência das leituras de 15 em 15 minutos. As correções da compensação barométrica foram feitas a partir de um sensor barométrico, instalado na parte externa em um dos poços.

Seguem as características dos pares de poços selecionados (Figura 1):

- P8-PM8: estão separados 231 m entre si, localizados em posição intermediária entre as áreas de recarga e descarga do sistema aquífero, próximos ao prédio da reitoria.

- P10-PM6: estão separados 125 m entre si, localizados na área de descarga local do sistema aquífero, na porção norte da área de estudo.

- P3-PM1: estão separados $45 \mathrm{~m}$ entre si, localizados na área de recarga do sistema aquífero, dentro da área do CDTN. O P3 encontrava-se em operação, permitindo a obtenção de parâmetros hidráulicos do sistema aquífero, como a transmissividade (T), vazão específica (Sy) e a condutividade hidráulica $(\mathrm{K})$. Os poços P3 e PM1 não foram abordados na análise da influência da precipitação na recarga, pois o P3 encontrava-se em operação, causando perturbações no PM1.

O monitoramento manual do nível da água foi feito semanalmente em dois poços profundos desativados (P4 e P2) e em um piezômetro (PM2), localizados na porção sul da área de estudo (Figura 1), utilizando um medidor de nível d'água com sensor elétrico-sonoro. O monitoramento teve início em 17/08/2012, no final do período de estiagem, até $01 / 05 / 2013$, de modo a se identificar o início e o término da ocorrência dos principais eventos de infiltração pluvial. Nos poços com medição manual do nível d'água (PM2, P2 e P4), a cada 7 dias foram obtidos dados de chuva acumulados quinzenalmente, para a análise da influência da precipitação na recarga. Enfatiza-se que 2013 foi um ano de precipitação atípica, com prolongamento das chuvas até maio.

Para melhor compreender a dinâmica da água subterrânea na área, identificando as principais regiões de recarga e de descarga, foram gerados os mapas potenciométricos representativos do aquífero granular e fissural. Os valores das cotas dos níveis d'água usados para gerar estes mapas são referentes às médias dos valores de NA monitorados.

\subsection{Análise estatística dos dados}

Todas as correlações foram precedidas de testes de normalidade das amostras de dados. Os testes de aderência Kolmogorov-Smirnov e 
Shapiro Wilk $(\mathrm{p}<0,05)$ foram aplicados aos dados de nível d'água monitorados nos conjuntos de poços profundos (PP) e piezômetros (PM).

Os resultados dos testes mostraram o comportamento não paramétrico desses dados, o que indica que o uso de testes de correlação de Spearman são os mais adequados a este caso.

\subsection{Análise de correlação cruzada}

A função de correlação cruzada (FCC) evidencia a relação entre duas variáveis temporais que não são necessariamente contemporâneas (SAMOHYL 2005). Para a determinação da FCC foi utilizado o software Microsoft Excel. Uma variável pode influenciar com algum tempo de atraso o comportamento de outra variável. Sem que haja uma clareza do tempo dessa defasagem não é possível identificar a correlação existente entre as mesmas. A aplicação deste método permite que se identifique a referida defasagem de tempo e, consequentemente, a correlação. Este período de defasagem pode ser determinado segundo a função de correlação cruzada e é comumente chamada de $\operatorname{lag}(k)$. De acordo com FERRARI \& KARMANN (2008) essa função é utilizada para análises de séries de entrada e de saída para $k>0$, sendo $k$ o tempo de defasagem da correlação entre as séries temporais X e Y (Equações 1 e 2).

$$
r_{x y}(k)=\frac{C_{x y}(\mathrm{k})}{\sigma_{\mathrm{x}} \sigma_{\mathrm{y}}} \text { Equação } 1
$$

$$
C_{x y}(k)=\frac{1}{n} \sum_{t=1}^{n-k}\left(x_{t}-\bar{x}\right)\left(y_{t+k}-\bar{y}\right) \text { Equação } 2
$$

Onde:

$\mathrm{r}_{x y(k)}$ corresponde à resposta do sistema ao input de acordo com o índice $(k)$;

(k) é o índice que determina o deslocamento temporal entre as séries x e y;

$\mathrm{C}_{\mathrm{xy}(k)}$ é a função de correlação cruzada de acordo com o índice $(k)$;

$\sigma_{\mathrm{x}}$ e $\sigma_{\mathrm{y}}$ são os desvios padrões das séries temporais $\mathrm{x}, \mathrm{y}$;

n é o comprimento da série temporal.

As entradas influenciam as saídas sempre que $\mathrm{r}_{\mathrm{xy}}(k)>0$ para $k>0$ (FERRARI \& KARMANN 2008). O tempo de defasagem no correlograma $\mathrm{r}_{\mathrm{xy}}(k)$ versus lag é obtido visualmente pelo maior valor positivo de $\mathrm{r}_{\mathrm{xy}}(k)$ plotado.

O objetivo dessa análise é avaliar o tempo decorrido entre os inputs de recarga do aquífero granular e do aquífero fissural. Dessa forma determina-se o tempo de percolação da água do aquífero granular para o fraturado, assumindo-se que ambos estejam hidraulicamente conectados.

Utilizou-se os dois pares de poços monitorados (PM6/P10 e PM8/P8: Piezômetro-Poço Profundo) com transdutores e que se encontravam sob condições naturais de variação do nível d'água para a investigação da conexão hidráulica entre os aquíferos poroso e fissural.

A FCC foi precedida de teste de correlação entre o nível freático e a precipitação medida. Confirmada a correlação, foi aplicada a FCC a fim de obter o tempo decorrido para a chuva começar a influenciar no comportamento potenciométrico.

\subsection{Cálculo da recarga}

O cálculo estimativo da recarga foi realizado somente para o aquífero granular pelo método da variação do nível estático nos piezômetros monitorados, segundo a equação empregada (HEALY \& COOK 2002):

$$
\mathrm{R}=\mathrm{Sy} \mathrm{dh} / \mathrm{dt}=\mathrm{Sy} \Delta \mathrm{h} / \Delta \mathrm{t} \text { Equação } 3
$$

Onde:

$\mathrm{R}$ é a recarga, Sy é a vazão específica, $\Delta \mathrm{h}$ ou dh é a variação do nível de água estático e $\Delta \mathrm{t}$ ou dt é a variação do tempo.

$\mathrm{O}$ valor de $\Delta \mathrm{h}$ num período hidrológico pode ser obtido de diversas formas, dentre elas, pela diferença entre o nível mínimo e máximo do nível d'água, ou pelo somatório de todas as elevações do nível d'água medidos (WAHNFRIED \& HIRATA 2005). No presente estudo, optou-se pelo somatório de todas as elevações correspondentes aos intervalos de medição automática, de 15 em $15 \mathrm{~min}$, resultando em valores mais detalhados do que os determinados nas medições manuais, que foram feitas semanalmente.

O método é muito sensível ao parâmetro Sy, tendo sido empregado o valor determinado em teste de bombeamento realizado no poço $\mathrm{P} 3 \mathrm{em}$ operação.

Os dados de precipitação foram adquiridos na Estação Meteorológica do CDTN/CNEN (EMET-CDTN), localizada no interior da área de estudo.

Os dados adquiridos foram diários e sistematizados posteriormente para o acumulado quinzenal, a fim de facilitar nas análises futuras. 
O método considera as seguintes premissas: i) toda elevação do nível d'água é oriunda da recarga; ii) toda água que chega à zona saturada adentra a porção em armazenamento. Considerou-se, portanto, que o fluxo de base, a evapotranspiração das águas subterrâneas e o fluxo em subsuperficie são iguais à zero (WAHNFRIED \& HIRATA 2005).

\subsection{Teste de bombeamento}

Os parâmetros condutividade hidráulica $(\mathrm{K})$, transmissividade $(\mathrm{T})$ e a vazão específica (Sy) do aquífero fissural foram determinados em testes de bombeamento realizados a partir dos dados de variação do nível d'água obtidos no transdutor instalado no poço ativo P3. Os dados foram analisados no software Aquifer Test (AQTESOLV Aquifer Test User's Manual, s.d.), no qual optou-se pelas soluções de Neuman e sua simplificação proposta por Cooper-Jacob, e de Theis, dadas as características do aquífero e do poço em questão.

\section{RESULTADOS}

Os fluxos de ambos os aquíferos, granular (Figura 3) e fissural (Figura 4), possuem sentido SW para NE, tendo como uma importante zona de recarga geral a porção $\mathrm{SW}$, nas instalações do CDTN, região com importante parcela do solo disponível para infiltração direta. A porção NE junto à entrada da UFMG (acesso pela Av. Antônio Carlos) é a região de descarga da área de estudo, por onde passa o córrego Engenho Nogueira (atualmente canalizado nesta área), local onde historicamente se registram alagamentos dentro do campus.

Constatou-se que o fluxo subterrâneo tem a mesma direção e sentido, tanto na estação seca como na chuvosa, e não se alteram ao longo dos anos analisados.

A superfície potenciométrica de ambos os aquíferos se conforma ao relevo e possui valores dos gradientes hidráulicos semelhantes: de 0,015 para o aquífero poroso e de 0,013 para o aquífero fissural.

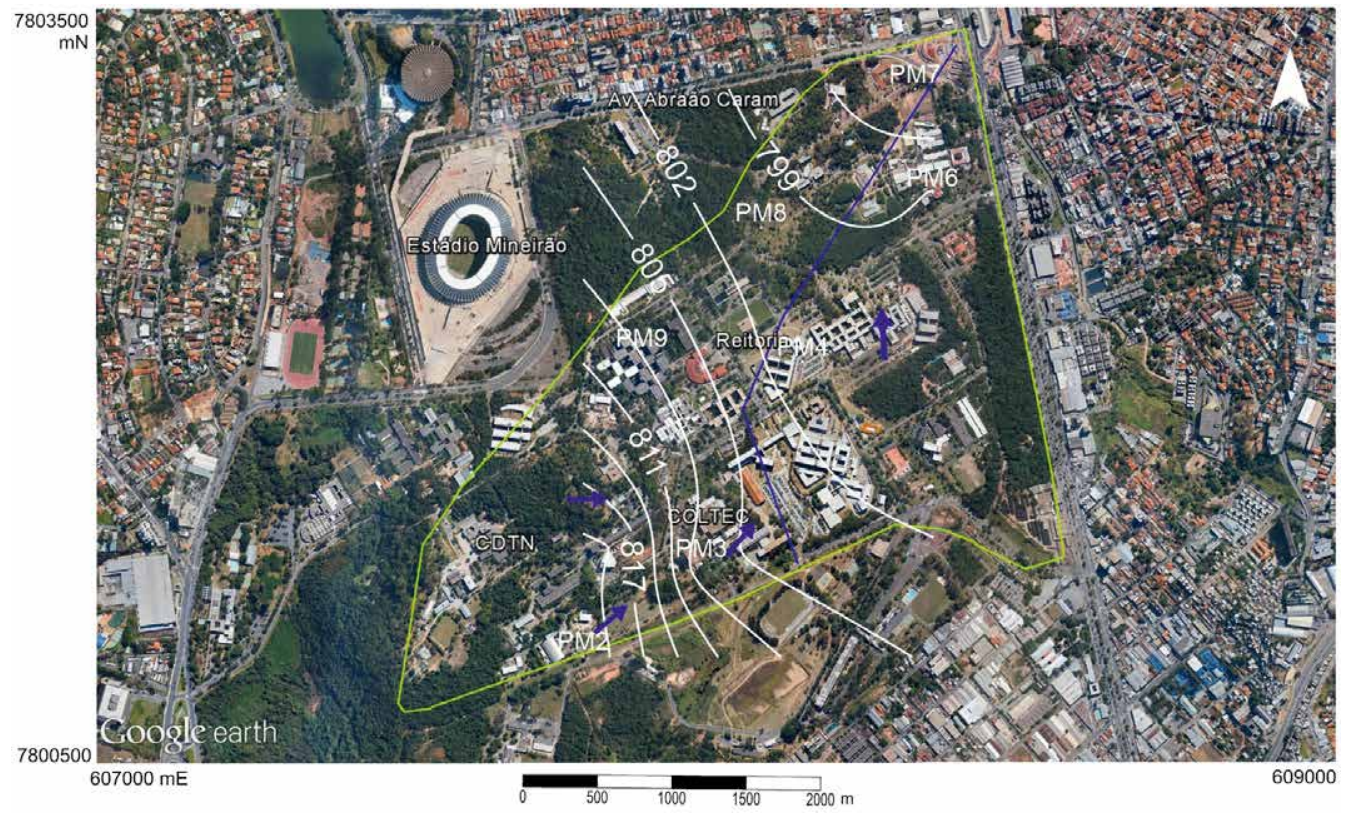

FIGURA 3 - Mapa potenciométrico do aquífero poroso. 


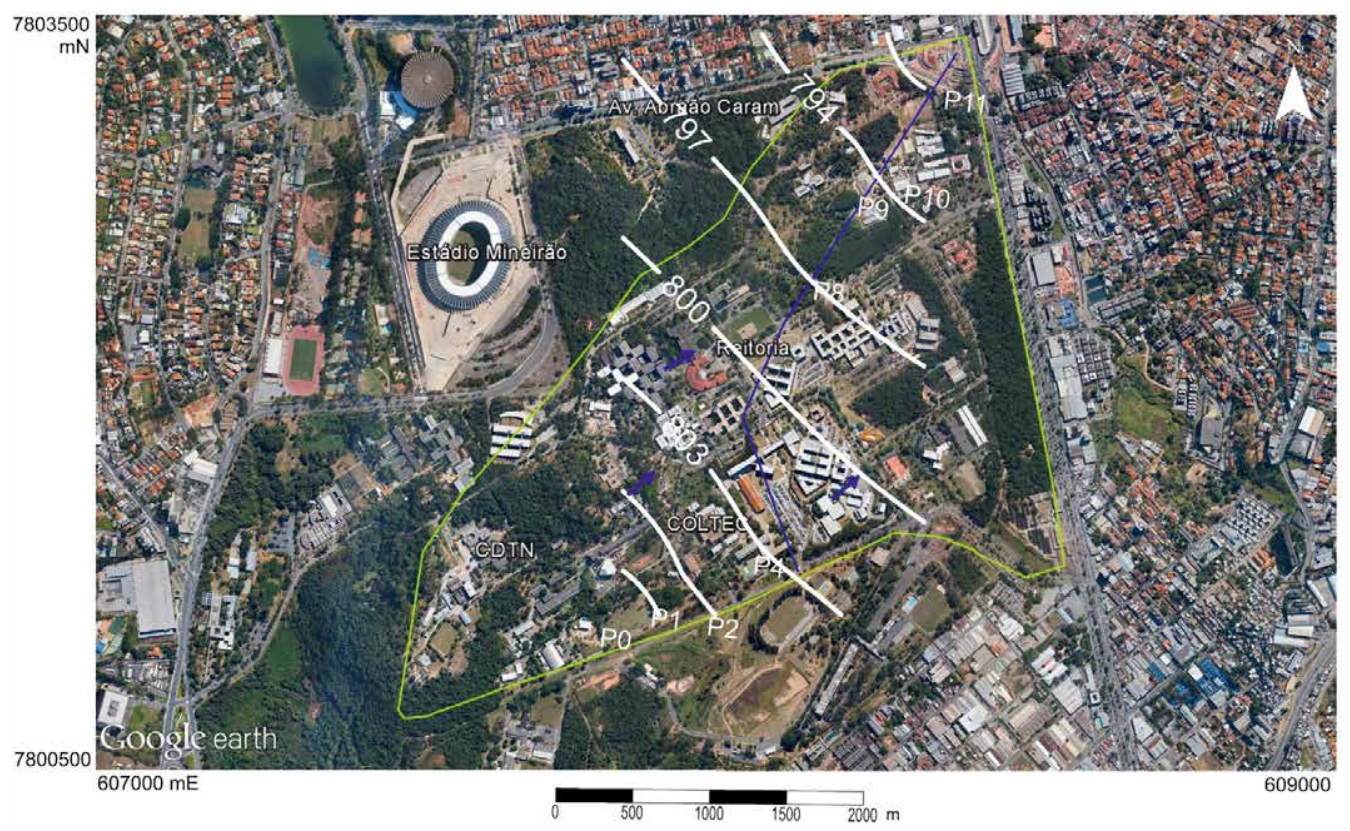

FIGURA 4 - Mapa potenciométrico do aquífero fissural/misto.

Análise da influência da precipitação na recarga

São apresentados nas figuras 5 e 6 o comportamento do nível de água em três piezômetros e quatro poços profundos, em resposta à precipitação no período de agosto/2012 a abril/2013.
Verifica-se uma notória defasagem de tempo entre os picos de elevação do nível d'agua e os da precipitação, tanto nos piezômetros como nos poços profundos, que será numericamente avaliada $a$ posteriori, por meio de correlações estatísticas e da FCC.

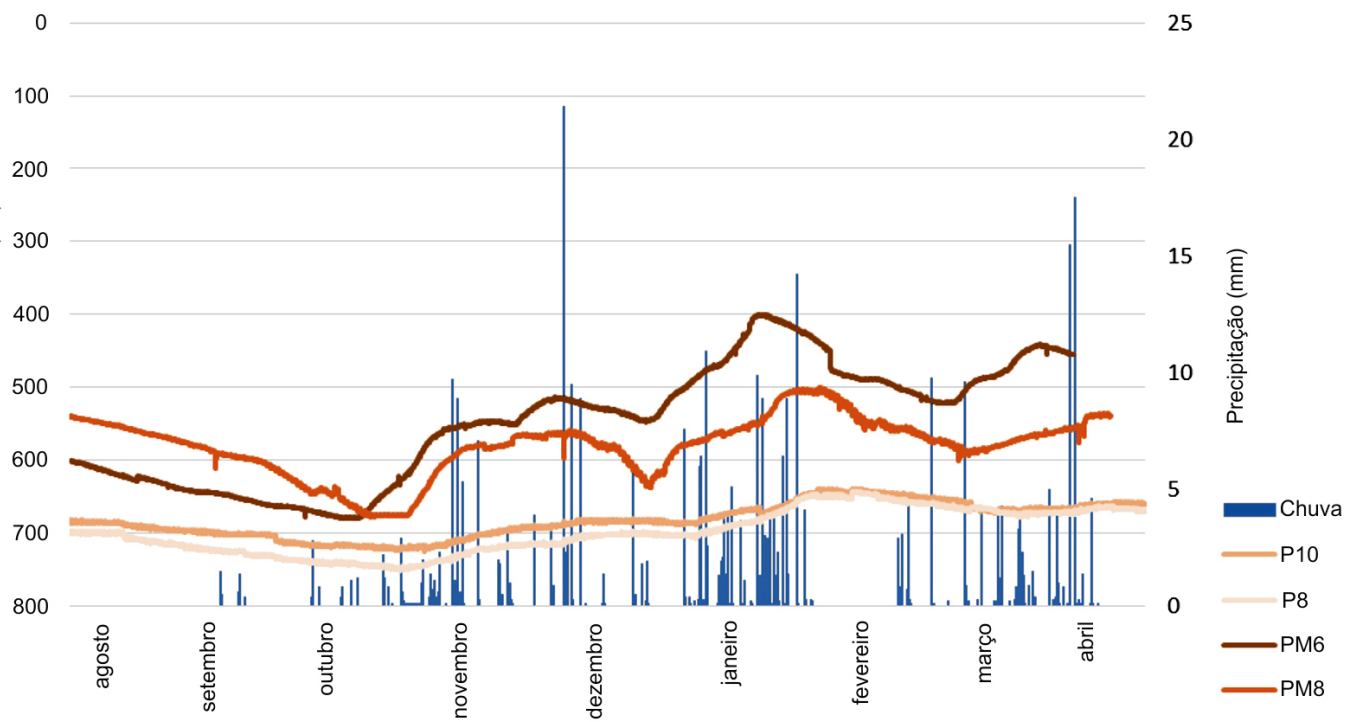

FIGURA 5 - Precipitação e profundidade do nível de água medida com transdutor de pressão nos piezômetros PM6 e PM8 e nos poços P10 e P8. 


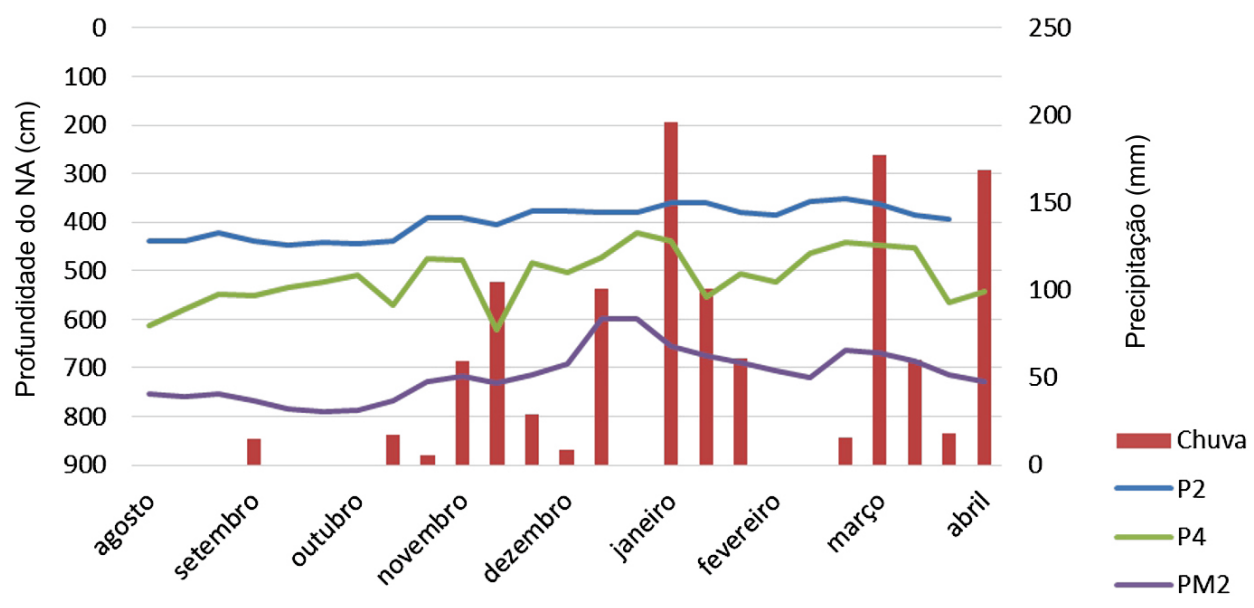

FIGURA 6 - Precipitação e profundidade do nível de água monitorado manualmente a cada 7 dias no piezômetro PM2 e nos poços P2 e P4.

Os valores de correlação de Spearman entre a variação do nível de água e a precipitação foram muito fracos nos poços com monitoramento automatizado $(r=-0,01$ a $-0,07)$, enquanto nos poços manuais se mostraram fracos $(r=-0,36)$ (Tabela 3$)$, para um nível de significância de $95 \%$.

TABELA 3 - Coeficiente de correlação de Spearman entre a Precipitação e a Profundidade do nível d'água (NA) para poços com transdutor de pressão e com leituras manuais semanais.

\begin{tabular}{cccc}
\hline \multicolumn{4}{c}{ NA x precipitação } \\
\hline \multicolumn{2}{c}{ Transdutor (frequência } & \multicolumn{2}{c}{ Manual } \\
\multicolumn{2}{c}{ de 15 em } & 15 min) & (frequência semanal) \\
\hline PM6 & $-0,07$ & P2 & $-0,36$ \\
PM8 & $-0,01$ & P4 & $-0,36$ \\
P8 & $-0,01$ & PM2 & $-0,36$ \\
P10 & $-0,02$ & & \\
\hline
\end{tabular}

Estas fracas correlações dos dados automatizados são explicadas pela intensa variação da pressão atmosférica ao longo do dia, que se reflete nas leituras de $15 \mathrm{em} 15 \mathrm{~min}$, efeito de pequenas variações piezométricas, ao passo que a precipitação varia mais lentamente. Além disso, essa correlação foi realizada com pares de dados correspondentes ao mesmo período, não levando em consideração o período de defasagem entre a precipitação e a resposta do nível de água a esse input de precipitação.

Considerando a frequência quinzenal de dados de Profundidade do nível d'água e de Precipitação acumulada correspondente, o grupo de poços com medição automatizada teve menor coeficiente de correlação $(\mathrm{p}<0,05)$ em relação aos poços com medição manual, tendo em comum as fracas correlações em ambos os grupos (Tabela 4).

TABELA 4 - Coeficiente de Correlação de Spearman entre Precipitação e a Profundidade do nível d'água com frequência quinzenal e mensal.

\begin{tabular}{|c|c|c|c|c|c|c|c|}
\hline \multicolumn{4}{|c|}{ Medições com frequência quinzenal } & \multicolumn{4}{|c|}{ Medições com frequência mensal } \\
\hline \multicolumn{2}{|c|}{ Poços com transdutores } & \multicolumn{2}{|c|}{$\begin{array}{c}\text { Poços com medida } \\
\text { manual }\end{array}$} & \multicolumn{2}{|c|}{ Poços com Transdutor } & \multicolumn{2}{|c|}{$\begin{array}{c}\text { Poços com medida } \\
\text { manual }\end{array}$} \\
\hline PM6 & $-0,32$ & $\mathrm{P} 2$ & $-0,36$ & PM6 & $-0,79$ & $\mathrm{P} 2$ & $-0,77$ \\
\hline PM8 & $-0,14$ & P4 & $-0,36$ & PM8 & $-0,70$ & P4 & $-0,38$ \\
\hline $\mathrm{P} 10$ & $-0,26$ & PM2 & $-0,36$ & P8 & $-0,51$ & PM2 & $-0,80$ \\
\hline P8 & $-0,16$ & & & $\mathrm{P} 10$ & $-0,55$ & & \\
\hline
\end{tabular}


Os valores negativos das correlações ocorrem porque os valores de precipitação aumentam com a chuva, e, numericamente, os valores de NA diminuem, contudo o que de fato diminui é a distância entre o NA e a boca do poço.

Considerando a frequência mensal de dados de Precipitação e de Profundidade do nível d'água, verificam-se valores de coeficiente de correlação forte (PM2), moderados (PM6, PM8, P2, P8, P10) e fraco (P4) (Tabela 4). Esse resultado é perfeitamente compatível com a condição hidrogeológica apresentada, pois o aquífero freático está mais deliberadamente exposto à precipitação direta. A fraca correlação em $\mathrm{P} 4$ deve-se à localização deste poço a cerca de 10 m do Córrego Engenho Nogueira, no seu trecho a céu aberto, que pode estar promovendo uma forte interação hidráulica localizada entre o córrego e o aquífero.

Os valores de correlação mais elevados nos dados de frequência mensal em relação ao quinzenal ratificam a diminuição da influência da intensa variação barométrica e a existência de um período de defasagem entre a precipitação e resposta do nível de água.

Confirmada a influência da precipitação na profundidade do nível d'água, foram feitos correlogramas de FCC com a finalidade de se identificar, em cada poço e piezômetro, qual o tempo gasto para que a infiltração pluvial atingisse de forma significativa o nível d'água de ambos os aquíferos. Foram usados dados diários e restritos aos poços com transdutores de pressão, de modo a se obter maior confiabilidade nos resultados. Obtiveram-se defasagens de tempo de 45 e 70 dias para os piezômetros e de 50 a 69 dias para os poços profundos (Tabela 5).

TABELA 5 - Defasagem de tempo (dias) entre a Precipitação e a Profundidade do nível d'água nos poços, por análise de FCC em poços com medição automatizada.

\begin{tabular}{cc|cc}
\hline Piezometro & $\begin{array}{c}\text { Lag } \\
\text { (dias) }\end{array}$ & $\begin{array}{c}\text { Poço } \\
\text { Profundo }\end{array}$ & $\begin{array}{c}\text { Lag } \\
\text { (dias) }\end{array}$ \\
\hline PM6 & 70 & P10 & 50 \\
PM8 & 45 & P8 & 69 \\
\hline
\end{tabular}

O nível d'água no PM8 responde completamente com 45 dias aos inputs de infiltração, isto é, 25 dias antes do que o PM6 (70 dias), mesmo estando ambos com praticamente a mesma profundidade máxima na estação seca $(6,8 \mathrm{~m}$ e 6,9 $\mathrm{m})$. Uma possível causa dessa grande diferença de resposta seria os contextos hidrogeológico e textural da zona não saturada de ambos os locais: PM6 atravessa em todo o seu perfil de $15 \mathrm{~m}$ de profundidade um solo residual de gnaisse com argilas que diminuem a permeabilidade do meio, atuando como um aquitardo. Por conseguinte, o tempo para a água atingir o aquífero é maior. Já PM8 atravessa uma camada de 3,9 m de aterro, na porção mais próxima à superfície, seguido de argila plástica orgânica até $6,6 \mathrm{~m}$ e de solo residual até $10 \mathrm{~m}$; ou seja, a camada de argila de 2,7 $\mathrm{m}$ de espessura diretamente abaixo do aterro pode estar funcionando como uma barreira hidráulica e resultando numa condição local de aquífero suspenso ou aquiclude, condição essa que pode estar provocando uma manutenção do nível de água em cotas mais elevadas por mais tempo, diminuindo, assim, o tempo de resposta das frentes de infiltração. Além disso, o tipo de aterro existente no local tende a ser bastante poroso, facilitando a infiltração.

Os poços profundos $\mathrm{P} 10$ e $\mathrm{P} 8$, situados na planície aluvionar do Córrego Engenho Nogueira, possuem médias de profundidade de nível d'água muito próximas entre si, ao redor de $7 \mathrm{~m}$. Seus perfis texturais são também muito semelhantes, constituídos de uma espessa camada de argila orgânica plástica, contínua, nos primeiros $6 \mathrm{~m}$ no $\mathrm{P} 10$ e nos primeiros $8 \mathrm{~m}$ no P8. Abaixo dessa camada argilosa, ocorrem intercalações de argila e areia a até $22 \mathrm{~m}$ (P8) e $24 \mathrm{~m}$ (PM8), em proporções semelhantes em cada perfil. Supõe-se que os $2 \mathrm{~m}$ de argila encontrados a mais no topo do solo onde se situa o $\mathrm{P} 8$ pode ser responsável pela diferença de resposta da recarga entre os dois locais: 19 dias a mais na localidade do P8 (69 dias) em relação ao P10 (50 dias).

Conexão hidráulica entre os aquíferos poroso e fissural

Os resultados da correlação dos dois pares de poços (PM6/P10 e PM8/P8) confirmam os resultados esperados, mostrando estatisticamente uma conexão hidráulica moderada entre os aquíferos, com resultados: $\mathrm{r}=0,783$ para o par $\mathrm{PM} 6 / \mathrm{P} 10$ e $\mathrm{r}=0,772$ para o par $\mathrm{PM} 8 / \mathrm{P} 8$, com significância $\mathrm{p}<0,05$. Mesmo na porção ao norte da área de estudo, onde ocorre uma lente de argila selante, que dificultaria esta conexão, os resultados mostraram boa correlação.

A FCC aplicada aos pares de poços PM6/P10 e PM8/P8 resultou em um período de um dia para a recarga começar a ocorrer (Figuras 7 e 8 ) em ambos os pares de poços. 


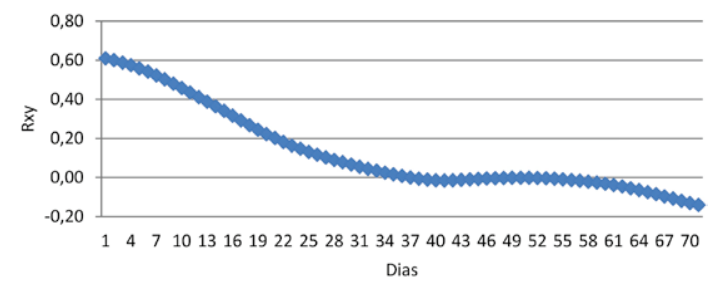

FIGURA 7 - Correlograma FCC entre NA de poço e piezômetro - PM6 e P10 ( $\mathrm{r}_{\mathrm{xy}}(\mathrm{k}=1 \mathrm{dia})$ ).

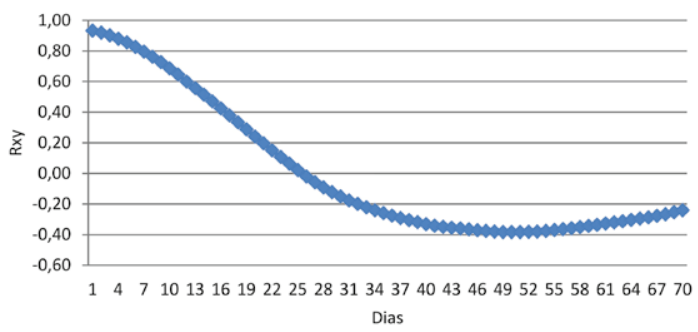

FIGURA 8 - Correlograma FCC entre NA de poço e piezômetro - PM8 e P8 ( $\mathrm{r}_{\mathrm{xy}(\mathrm{k}=1 \mathrm{dia})}$

\section{Cálculo da recarga}

Para o cálculo da recarga anual (3) utilizou-se o valor de $S y=0,1$, determinado em testes de bombeamento com dados do P3 que esteve em operação ao longo do monitoramento (Tabela 6).
Os resultados dos testes de bombeamento apontam para variações nos valores da transmissividade (T) e de coeficiente de armazenamento (S), com valores de rendimento específico (Sy) sem qualquer alteração (Tabela 6).

Os valores de $\Sigma \Delta \mathrm{h}$ foram os obtidos na escala de tempo semanal, somando-se todas as elevações do nível d'água. Apesar de o período monitorado ter sido de oito meses e meio salienta-se que a recarga calculada é representativa do ano hidrológico 2012/2013, uma vez que no período não monitorado (maio, junho, julho e agosto) a precipitação foi insignificante e o $\Delta \mathrm{h}$ foi predominantemente negativo entre uma medição e outra. A chuva que ocorreu no intervalo não monitorado (02/05/2013 a $16 / 08 / 2013)$ foi de apenas $59 \mathrm{~mm}$ (5\% em relação ao ano hidrológico) e não teria trazido elevações significativas de $\Delta \mathrm{h}$, tendo por isso sido descartada.

Os valores pontuais de recarga (Tabela 7) foram bastante semelhantes no PM2 e PM8, de 264 $\mathrm{mm}$ ( $28 \%$ de precipitação) e $279 \mathrm{~mm}$ ( $29 \%$ de precipitação), ambos localizados sob vegetação arbórea, enquanto o maior valor ocorreu em PM6 com 390 mm (41\% de Precipitação), localizado em área de gramíneas. Trabalhos na área de estudo efetuados por CARVALHO FILHO (1997) apresentaram valores de recarga variando pontualmente de $20 \%$ a $42 \%$ da precipitação anual.

TABELA 6 - Parâmetros hidráulicos obtidos a partir de teste de bombeamento com dados do transdutor instalado no P3.

\begin{tabular}{cccccccccccc}
\hline & 1 & 2 & 3 & 4 & 5 & 6 & 7 & 8 & 9 & 10 & Média \\
\hline $\mathrm{T}$ & 0,06 & 0,02 & 0,06 & 0,03 & 0,04 & 0,05 & 0,05 & 0,04 & 0,08 & 0,07 & 0,05 \\
$\mathrm{~S}$ & $1,42^{-3}$ & $5,94^{-3}$ & $4,86^{-3}$ & $1,02^{-2}$ & $2,45^{-3}$ & $4,01^{-3}$ & $6,90^{-3}$ & $3,47^{-3}$ & $6,90^{-6}$ & $5,94^{-3}$ & $5,12^{-3}$ \\
$\mathrm{Sy}$ & 0,1 & 0,1 & 0,1 & 0,1 & 0,1 & 0,1 & 0,1 & 0,1 & 0,1 & 0,1 & 0,1 \\
\hline
\end{tabular}

T: transmissividade $\left(\mathrm{m}^{3} \mathrm{~h}^{-1}\right), \mathrm{S}$ : coeficiente de armazenamento, Sy: vazão específica $\left(\mathrm{m}^{3} \mathrm{~h}^{-1} \mathrm{~m}^{-1}\right)$

TABELA 7 - Valores de recarga calculados pelo método de variação do nível d'água para 8,5 meses de monitoramento.

\begin{tabular}{cccccc}
\hline Piezômetro & $S y^{(a)}$ & $\begin{array}{c}\Sigma \Delta h \\
(\mathrm{~mm})\end{array}$ & $\begin{array}{c}\text { Recarga } \\
\left(\mathrm{mm} \mathrm{ano}^{-1}\right)\end{array}$ & $\begin{array}{c}\% \\
\text { Precipitação }\end{array}$ & $\begin{array}{c}\text { Precipitação no periodo } \\
\text { monitorado 2012/2013 } \\
(\mathrm{mm})\end{array}$ \\
\hline PM2 & 0,1 & 2.640 & 264 & 28 & 956 \\
PM6 & 0,1 & 3.900 & 390 & 41 & 956 \\
PM8 & 0,1 & 2.790 & 279 & 29 & 956 \\
\hline
\end{tabular}

(a) obtido por dados do transdutor do P3(CDTN) em operação durante monitoramento ago/2012 a mai/2013. 
Foi determinado o volume anual de água incorporado ao aquífero granular por meio da recarga a partir do produto da $\Sigma \Delta$ h dos poços e da vazão específica (Sy).

Esse cálculo não se aplica, a rigor, ao aquífero fissural, porém, optou-se por adaptar e usar um valor de "Sy" médio, teórico, a partir dos valores calculados por MARÉCHAL et al. (2009) e HEALY \& COOK (2002), de 0,003, 0,09 e 0,015 para aquíferos fissurais, que resultou em 0,036 (Tabela 8).
O volume da recarga direta da chuva ao aquífero granular em 2012/2013 foi de $775.000 \mathrm{~m}^{3}$ (Tabela 8), enquanto no fissural foi de $109.200 \mathrm{~m}^{3}$. Considerando que a recarga do aquífero fissural é oriunda do aquífero granular, o volume líquido de água adicionado ao aquífero granular foi na verdade de $685.000 \mathrm{~m}^{3}$ ano $^{-1}$. Sendo assim, cerca de $14 \%$ da água de recarga do aquífero granular recarregaria o aquífero fissural. $\mathrm{O}$ excedente do aquífero poroso que não recarrega o aquífero fissural percola lateralmente, contribuindo para o escoamento básico da bacia.

TABELA 8 - Cálculo do volume de água recarregado em cada aquífero anualmente.

\begin{tabular}{cccccccc}
\hline Po̧̧o & $\begin{array}{c}\Sigma \Delta h \\
(\mathrm{~m})\end{array}$ & Sy & $\Sigma \Delta h \times S y$ & $\begin{array}{c}\text { Média } \\
\Sigma\end{array} \mathrm{h} \times \mathrm{Sy}$ & Area $\left(\mathrm{m}^{2}\right)$ & $\begin{array}{c}\text { Volume total } \\
\text { de recarga } \\
\left(\mathrm{m}^{3}\right)\end{array}$ & $\begin{array}{c}\text { Volume líquido } \\
\text { de recarga } \\
\left(\mathrm{m}^{3}\right)\end{array}$ \\
\hline PM2 & 2,64 & 0,1 & 0,26 & & & & \\
PM6 & 3,90 & 0,1 & 0,39 & 0,31 & 2.500 .000 & 775.000 & 665.800 \\
PM8 & 2,79 & 0,1 & 0,28 & & & & \\
\hline P2 & 1,55 & 0,036 & 0,0558 & & & & \\
P4* & 0,70 & - & - & & & & \\
P8 & 1,15 & 0,036 & 0,0414 & 0,04368 & 2.500 .000 & 109.200 & \\
P10 & 0,94 & 0,036 & 0,0338 & & & & \\
\hline
\end{tabular}

P4* não contabilizado por causa da sua natureza locacional restrita na área, junto ao córrego aberto.

\section{CONCLUSÕES}

Verificou-se uma forte conexão hidráulica entre os aquíferos fissural e granular, confirmada pelas correlações estatísticas aplicadas às séries de profundidade de nível d'água. Esta conexão hidráulica, caracterizada pela influência do nível potenciométrico do aquífero granular sobre o nível do aquífero fissural apresentou resposta quase imediata (de um dia), determinada pela Função de Correlação Cruzada.

As defasagens de tempo entre a precipitação e a sua respectiva influência significativa nos níveis potenciométricos, variaram de 45 e 70 dias para os piezômetros (aquífero granular) e de 50 a 69 dias para os poços profundos (aquífero fissural).

As recargas foram medidas para o meio granular, cujos resultados variaram de 28 a $41 \%$ da precipitação do ano hidrológico 2012/2013. Uma avaliação preliminar determinou que cerca de $14 \%$ da água da recarga do aquífero granular chegaria ao fissural $\left(109.200 \mathrm{~m}^{3}\right)$.
Não existe na literatura específica um consenso de valor sobre o volume seguro a ser explotado dos aquíferos. Porém, os resultados obtidos constituem uma fonte de referência que pode servir de base para o gerenciamento dos recursos hídricos subterrâneos do campus Pampulha da UFMG.

\section{AGRADECIMENTOS}

Os autores deste artigo gostariam de agradecer a CAPES, pela bolsa de mestrado cedida e ao CDTN, pela cessão dos dados de precipitação e de nível d'água, além do apoio técnico ao longo do trabalho. Agradecem também aos relatores da Revista pelo apoio prestado no processo de publicação.

\section{REFERÊNCIAS BIBLIOGRÁFICAS}

ANA - AGÊNCIA NACIONAL DE ÁGUAS. 2007. Disponibilidade e demanda de recursos hídricos no Brasil. Superintendência de Planejamento de Recursos Hídricos, Cadernos de Recursos Hídricos, 2, Brasília. 
BEATO, D.A.C.; MEDEIROS, M.J.; DREWS, M.G.P.; DUTRA, G.M. 2003. Impactos Urbanos em Águas Subterrâneas: Bacia da Lagoa da Pampulha, Belo Horizonte - MG. Belo Horizonte. Revista Água Subterrânea, 17: 49-68.

CARVALHO FILHO, C.A. 1997. Caracterização Hidrodinâmica de Parte do Sistema Aquífero da Bacia do Campus - UFMG/ Belo Horizonte, Minas Gerais. Faculdade de Engenharia, Universidade Federal de Minas Gerais, Belo Horizonte, Dissertação de Mestrado, 162 p.

COSTA, W.D. 2002. Caracterização das condições de uso e preservação das águas subterrâneas do município de Belo Horizonte - MG. Instituto de Geociências, Universidade de São Paulo, Tese de doutoramento, 350 p. + anexos.

CPRM - COMPANHIA DE PESQUISA DE RECURSOS MINEIRAIS. 2001. Projeto Pampulha: Estudo hidrogeológico da bacia da Pampulha. D.A.C. Beato (Org.), Belo Horizonte, CPRM/PHB/P, $151 \mathrm{p}$.

FEITOSA, F.A.C.; MANOEL FILHO, J. (Org). 2008. Hidrogeologia Conceitos e Aplicações. CPRM/REFO, LABHID, UFPE, Fortaleza, $3^{\mathrm{a}}$ ed., $391 \mathrm{p}$.

FERRARI, J.A.; KARMANN, I. 2008. Comportamento hidrodinâmico de sistemas cársticos na Bacia do Rio Betari, Município de Iporanga - SP. Geologia USP Série Cientifica, 8(1): $1-13$.

HEALY, R.W.; COOK, P.G. 2002. Using groundwater levels to estimate recharge. Hydrogeology Journal, 10(1): 91-109.
MARÉCHAL, J.C.; VARMA, M.R.R.; RIOTTE, J.; VOUILLAMOZ, J.M.; MOHAN KUMAR, M.S.; RUIZ, L.; SEKHAR, M.; BRAUN, J.J. 2009. Indirect and direct recharges in a tropical forested watershed: Mule Hole, India. Journal of Hydrology, 364(3-4): 272-284.

MARQUES RIBEIRO, J.P.; VELÁSQUEZ, L.N.M.; CARVALHO FILHO, C.A.; FLEMING, P.M. 2014. Análise da Recarga no Sistema Aquífero Granular e Fissural na Área do Campus Pampulha da Universidade Federal de Minas Gerais. Geonomos, 22(2): 28-43.

REBOUÇAS, A.C. 2002. Águas Subterrâneas. In: A.C. Rebouças, B. Braga, J.G. Tundisi (Orgs.) Águas Doces no Brasil: capital ecológico, uso e conservação. Escrituras, São Paulo, p.433-460.

SAMOHYL, R.W. 2005. Introdução à Estatística e Métodos de Previsão em Séries Temporais: Teoria Aprofundada e Prática Simplificada. Universidade Federal de Santa Catarina/Núcleo de Normalização e Qualimetria-NQQ, Florianópolis, Cap. 3, p.1-28.

VASCONCELOS, S.M.S. 2005. Avaliação da Recarga Subterrânea Através da Variação do Nível Potenciométrico no Aquífero Dunas/ Paleodunas em Fortaleza, Ceará. Revista Brasileira de Recursos Hídricos, 10(2): 49-57.

WAHNFRIED, I.; HIRATA, R.C.A. 2005. Comparação de Métodos de Estimativa de Recarga de Aquíferos em Uma Planície Aluvionar na Bacia Hidrográfica do Alto Tietê (São Pau1o). Revista Brasileira de Recursos Hidricos, 10(2): 15-25.

\section{Endereço dos autores:}

João Pedro Marques Ribeiro - Programa de Pós-Graduação em Geociências, Instituto de Geociências, Universidade Federal de Minas Gerais. Av. Antônio Carlos, 6627, CEP 31270-901, Belo Horizonte, Brasil.E-mail: marquesribeiroster@gmail.com

Leila Nunes Menegasse Velásques - Instituto de Geociências, Universidade Federal de Minas Gerais. Av. Antônio Carlos, 6627, CEP 31270-901, Belo Horizonte, Brasil.E-mail: menegase@yahoo.com.br

Carlos Alberto de Carvalho Filho - Centro de Desenvolvimento da Tecnologia Nuclear- CDTN. Av. Antônio Carlos, 6627, CEP 31270-901, Belo Horizonte, Brasil.E-mail: cacf@cdtn.br 